\title{
SCIENTIFIC REPORTS

\section{OPEN First molecular detection of Toxoplasma gondii in vegetable samples in China using qualitative, quantitative real-time PCR and multilocus genotyping}

\author{
Anna Lass ${ }^{1,2^{*}}$, Liqing $\mathrm{Ma}^{2}$, loannis Kontogeorgos ${ }^{2,3}$, Xueyong Zhang ${ }^{2}$, Xiuping $\mathrm{Li}^{2}$ \& \\ Panagiotis Karanis ${ }^{2,4,5}$
}

Toxoplasma gondii infection is becoming increasing problem in China but there is no data concerning contamination of vegetables intended for consumption with this parasite. The aim of the present study was to investigate fresh vegetables originated from open markets located in the Xining City, the Qinghai-Tibet Plateau (OTP), P.R. China for their contamination with T. gondii. A total of 279 fresh vegetable samples were collected and analysed using real-time PCR assay targeting B1 gene and multilocus genotyping. T. gondii DNA was found in 10 (3.6\%) samples tested; eight of them represented $T$. gondii type I and remaining two $T$. gondii type II. The approximate level of contamination of positive vegetables samples, estimated based on quantitative real-time PCR (qPCR), ranged between less than one and $27000 \mathrm{~T}$. gondii oocysts per sample, with majority not exceeding several oocysts per sample. The results of the study confirmed that $T$. gondii is present in vegetables offered in open markets in the Qinghai province, P.R. China; eating them unwashed and raw may therefore pose a threat to consumers. This is the first investigation describing $T$. gondii detection in fresh vegetables intended for consumption collected from the territory of P.R. China using sensitive molecular tools.

\begin{abstract}
Introduction
Toxoplasma gondii is a cosmopolitan protozoan parasite able to infect humans and warm-blooded animals. Toxoplasmosis is one of the most prevalent parasitic infections in humans ${ }^{1-3}$. The disease is generally asymptomatic in immunocompetent individuals, it may take, however, a severe course up to life-threatening conditions in immunodeficient patients $s^{4}$, as well as in immature foetuses and infants, if the mother suffered from primary infection during pregnancy,6.

There are two main routes of acquiring T. gondii infection: consumption of raw and undercooked meat of infected animals containing cysts filled with parasites or accidental ingestion of oocysts excreted to the environment with faeces of infected Felidae, being the only definitive hosts of the parasite ${ }^{7-11}$. Presence of T. gondii has been confirmed in water, soil, and air in different parts of the world, for example in Poland ${ }^{12-14}$, Germany ${ }^{15}$, France $^{16,17}$, Scotland $^{18}$, Brazil $^{19,20}$, Ecuador ${ }^{21}$, Iran ${ }^{22,23}$ and Turkey ${ }^{24}$. Oocysts may also persist on the surface of fruit and vegetables; experiments have demonstrated that they may stay viable on raspberries stored at $4^{\circ} \mathrm{C}$ for eight weeks ${ }^{25}$. Subsequent environmental studies confirmed presence of T. gondii in fresh fruit and vegetables samples indicating them as potential source of infection in humans ${ }^{26-29}$.
\end{abstract}

${ }^{1}$ Department of Tropical Parasitology, Institute of Maritime and Tropical Medicine in Gdynia, Medical University of Gdansk, 9b Powstania Styczniowego Str., 81-519, Gdynia, Poland. ${ }^{2}$ State Key Laboratory of Plateau Ecology and Agriculture, Center for Biomedicine and Infectious Disease, Qinghai University, 1\#Wei'er Road, Qinghai Biological Scientific Estate Garden, Xining, 810016, P.R. China. ${ }^{3}$ Marine Sciences Department, School of Environment, University of the Aegean, University Hill, 88 100, Mytilene, Greece. ${ }^{4}$ Cologne University, Medical Faculty and University Hospital, Cologne, Germany. ${ }^{5}$ University of Nicosia, Medical School, 46 Makedonitissas Avenue, CY-2417, P.O. Box 24005, CY-1700, Nicosia, Cyprus. *email: anna.lass@gumed.edu.pl 
There are three major genetic lineages of T. gondii (I, II, III) defined, frequently observed in Europe and North America $^{30}$ and a rising number of atypical genotypes present in different parts of the world ${ }^{31-34}$. The most common genotype of Toxoplasma found in Asia is genotype ToxoDB\#9 (Chinese 1) with vast majority isolates detected in China ${ }^{35-38}$, but also found in Sri Lanka and Vietnam ${ }^{35,39}$. Type I is mostly present in eastern parts of Asia including South Korea, eastern provinces of China, peninsular Malaysia and Myanmar ${ }^{35}$. Less frequent in Asia are genotypes ToxoDB\#1 and \#3 (type II). Predominating in Europe, T. gondii type II is present in western and central Asia including Turkey, Qatar, Iran and the western provinces of China, which suggests a continuum between type II and Chinese 1 in the Eurasian continent ${ }^{35}$. In-depth sequencing studies suggest the same ancestral origin for type II and Chinese $1^{40-42}$ and studies on migration pathways for Toxoplasma also support the hypothesis that Chinese 1 preceded type $\mathrm{II}^{35}$. Genotypes ToxoDB\#2 (type III) together with atypical genotypes are the least prevalent in China ${ }^{35}$. Genotyping of Toxoplasma isolates coming from environmental samples has not been performed in China yet.

Toxoplasmosis in China is a consistent problem, despite being lower ${ }^{43}$ than the commonly accepted world average ${ }^{1,44}$; according to nationwide studies involving several thousands of examined humans, the national prevalence of toxoplasmosis fluctuated from $5.9 \%$ in the early ' $90 \mathrm{~s}^{45}$ to $7.9 \%$ in the ' $00 \mathrm{~s}^{46}$. A more recent nationwide study involving 2,008,561 women before pregnancy reported even lower prevalence $(2.6 \%)^{47}$, depicting a decreasing trend in younger generations in rural areas. Similar trend has been identified in the nationwide survey as well $^{46}$, where the highest prevalence regards citizens over 80 years old. There are also differences in the prevalence of the disease between different ethnic groups ${ }^{46,48}$, which are merely reflecting the differences in the exposure to the parasite relevant to occupational and societal (rural - urban residence) conditions and eating habits.

Regarding detection of Toxoplasma in the food chain, the majority of studies is focused on commercially raised livestock such as sheep ${ }^{49,50}$, goats ${ }^{51,52}$, bovines ${ }^{53,54}$, swine ${ }^{55,56}$ and poultry ${ }^{57,58}$. Attention has been given, recently, into commercially available meat as well ${ }^{59-64}$. This is important since traditional eating habits in some regions of China include consumption of raw or undercooked meat ${ }^{65}$, which has been associated along with domestic hygiene measures and consumption of raw milk with increased infection rates in China ${ }^{48,66-68}$ and in other countries ${ }^{69,70}$. Nevertheless, the foodborne route of toxoplasmosis through meat consumption has been well documented both globally and in China. The risk resulting from attachment of oocysts in vegetables and fruits, however, has not been studied extensively. In China particularly, we did not find any investigation regarding occurrence of Toxoplasma in fresh vegetables or fruits. Presence of T. gondii has been confirmed so far only in soil samples in different regions of the country, including north-western (Qinghai and Gansu), central (Hubei), north-eastern (Heilongjiang) and eastern (Jiangsu) provinces ${ }^{71-74}$ which demonstrates contamination of the environment with this parasite, and makes contamination of fresh fruit and vegetables likely.

The aim of the present study was to estimate the possible occurrence of $T$. gondii in vegetables available for consumers in open markets in Xining City, Qinghai province, P.R. China as well as to determine oocysts charge (number of dispersive forms of parasite) of investigated samples and genotype of obtained T. gondii isolates via sensitive molecular tools (real-time PCR, qPCR, multilocus PCR/RFPL analysis).

\section{Samples and Study Area}

A total of 279 fresh vegetable samples were collected between January and August 2016 from open markets located in the Xining City, Qinghai Province, western China (Fig. 1). Following vegetables were collected and examined: lettuce (Lactuca sativa) $(\mathrm{n}=71)$, spinach (Spinacia oleracea) $(\mathrm{n}=50)$, pak choi (Brassica rapa subsp. chinensis) $(\mathrm{n}=34)$, Chinese cabbage (Brassica pekinensis) $(\mathrm{n}=26)$, rape (Brassica napus) $(\mathrm{n}=22)$, Asparagus (Asparagus officinalis) $(\mathrm{n}=18)$, Chrysanthemum coronarium $(\mathrm{n}=16)$, endive (Cichorium endivia) $(\mathrm{n}=14)$, Chinese chives (Allium tuberosum) $(\mathrm{n}=11)$, cabbage (Brassica oleracea $\mathrm{L}$. var. capitata) $(\mathrm{n}=9)$, red cabbage (Brassica oleracea) $(\mathrm{n}=8)$. The samples were placed in disposable bags and transported to the laboratory.

Origin of vegetables. Vegetables available at open markets in Xining City are taken from the Qinghai-Tibet Plateau Agricultural Products Distribution Centre, a big hub for agricultural products. Only about $10 \%$ of them are grown in the Qinghai Province and the vast majority are transported there from other provinces including: Sichuan, Shandong, Shaanxi, Henan, Yunnan and Gansu provinces (Fig. 1). We were not able, however, to identify the origin of each separate vegetable that was sampled. Vegetables are cultured in greenhouses and farmlands which are located in the suburbs of the cities or in rural areas close to countryside. These places may attract animals including cats being definitive hosts of T. gondii and contamination of plants with oocysts is probable.

\section{Results}

In total, 279 fresh vegetable samples originated from open markets in the Xining City, QTP, P.R. China were examined with real-time PCR assays based on the T. gondii B1 gene. The presence of T. gondii DNA was recorded in 10 (3.6\%) samples investigated, including lettuce, spinach, Chinese cabbage (pak choi), red cabbage and rape samples (Table 1, Fig. 2). Sequencing of positive samples and comparison with the T. gondii sequence deposited in the GenBank displayed that the obtained nested PCR products were fragments of the T. gondii B1 gene (Table 2). Samples representing remaining types of vegetables were negative for Toxoplasma DNA (Table 1). The IPC test excluded presence of PCR inhibition in investigated samples that could influence the results (details are available in Supplementary Table S3).

Genotyping of ten positive samples using set of ten different genetic markers (SAG1, SAG2, SAG3, BTUB, GRA6, c22-8, c29-2, L358, PK1, Apico) showed that the majority (eight) of obtained Toxoplasma isolates represent $T$. gondii genotype I. In case of the remaining two positive samples $T$. gondii genotype II was detected (Table 2).

Regarding sampling period, the majority of vegetable samples positive for Toxoplasma DNA were detected during summer months, 5/104 (4.8\%) and 2/40 (5\%) in July and August respectively (Table 1). Lower number 


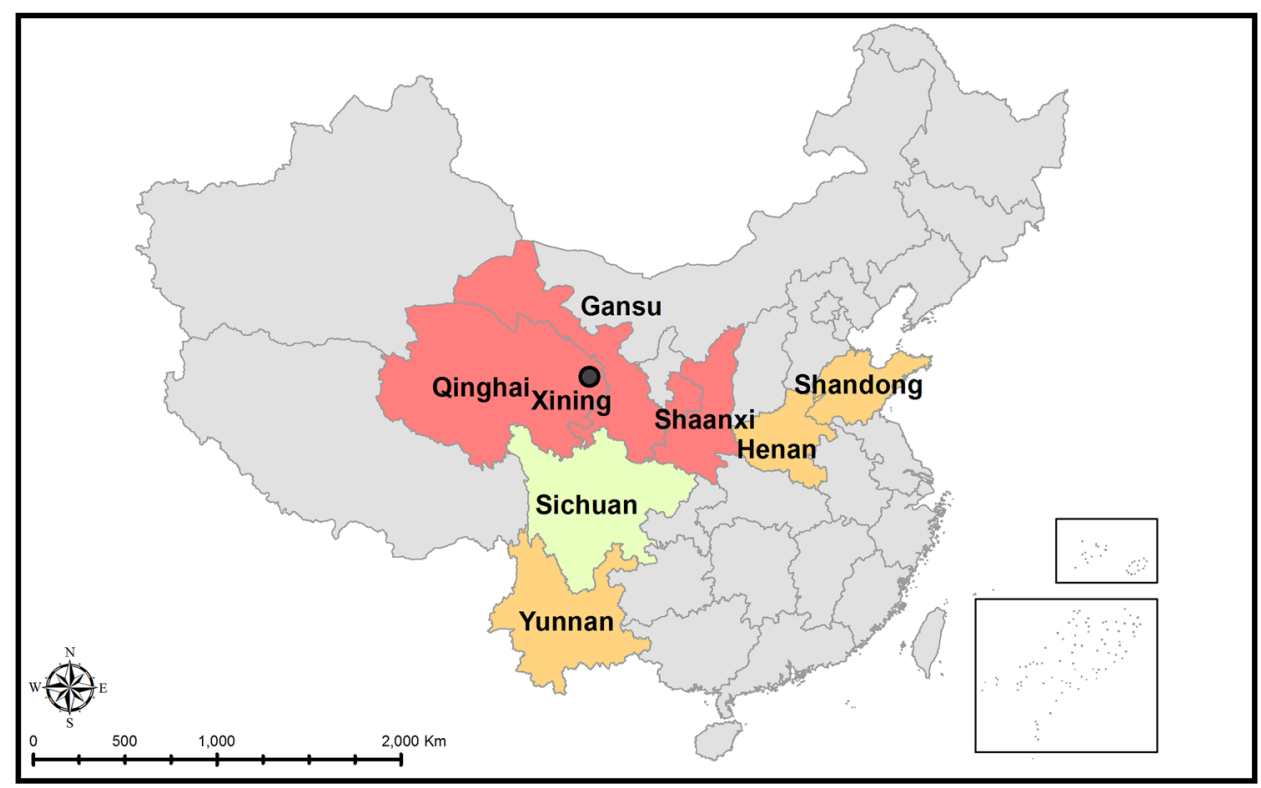

Figure 1. Location of sampling place (open markets) - Xining City, Qinghai Province, P.R. China and provinces where investigated vegetables grow. Colours represent occurrence of particular genotypes in Chinese provinces ${ }^{35}$ : pink refers to provinces where type II is prevalent; yellow refers to provinces where Chinese 1 genotype is prevalent and type I is common; olive represents province with scarce data about prevalence of $T$. gondii genotypes.

\begin{tabular}{|c|c|c|c|c|c|c|c|c|c|c|}
\hline \multirow[b]{3}{*}{ Type of the sample } & \multicolumn{10}{|c|}{ Samples investigated with real-time PCR } \\
\hline & \multicolumn{2}{|c|}{ January } & \multicolumn{2}{|c|}{ March } & \multicolumn{2}{|l|}{ July } & \multicolumn{2}{|c|}{ August } & \multicolumn{2}{|c|}{ Total samples } \\
\hline & No. & $(\%)$ & No. & $(\%)$ & No. & $(\%)$ & No. & $(\%)$ & No. & $(\%)$ \\
\hline Lettuce (Lactuca sativa) & $0 / 6$ & - & $0 / 2$ & - & $3 / 48$ & $(6.2)$ & $2 / 15$ & $(13.3)$ & $5 / 71$ & $(7.0)$ \\
\hline Spinach (Spinacia oleracea) & $0 / 15$ & - & $0 / 0$ & - & $2 / 27$ & $(7.4)$ & $0 / 8$ & - & $2 / 50$ & $(4.0)$ \\
\hline Pak choi (Brassica rapa subsp. Chinensis) & $1 / 15$ & $(6.7)$ & $0 / 9$ & - & $0 / 10$ & - & $0 / 0$ & - & $1 / 34$ & $(2.9)$ \\
\hline Chinese cabbage (Brassica pekinensis) & $0 / 12$ & - & $0 / 13$ & - & $0 / 1$ & - & $0 / 0$ & - & $0 / 26$ & - \\
\hline Rape (Brassica napus) & $1 / 12$ & $(8.3)$ & $0 / 0$ & - & $0 / 3$ & - & $0 / 7$ & - & $1 / 22$ & $(4.5)$ \\
\hline Asparagus (Asparagus officinalis) & $0 / 14$ & - & $0 / 4$ & - & $0 / 0$ & - & $0 / 0$ & - & $0 / 18$ & - \\
\hline Chrysanthemum coronarium & $0 / 9$ & - & $0 / 1$ & - & $0 / 6$ & - & $0 / 0$ & - & $0 / 16$ & - \\
\hline Endive (Cichorium endivia) & $0 / 0$ & - & $0 / 0$ & - & $0 / 8$ & - & $0 / 6$ & - & $0 / 14$ & - \\
\hline Chinese chives (Allium tuberosum) & $0 / 9$ & - & $0 / 1$ & - & $0 / 0$ & - & $0 / 1$ & - & $0 / 11$ & - \\
\hline Cabbage (Brassica oleracea L. var. capitata) & $0 / 6$ & - & $0 / 3$ & - & $0 / 0$ & - & $0 / 0$ & - & $0 / 9$ & - \\
\hline Red cabbage (Brassica oleracea) & $1 / 2$ & $(0.5)$ & $0 / 2$ & - & $0 / 1$ & - & $0 / 3$ & - & $1 / 8$ & $(1.2)$ \\
\hline Total results & $3 / 100$ & $(3.0)$ & $0 / 35$ & $(0.0)$ & $5 / 104$ & $(4.8)$ & $2 / 40$ & $(5.0)$ & $10 / 279$ & $(3.6)$ \\
\hline Monthly/Total results & $3 / 279$ & $(1.0)$ & $0 / 279$ & $(0.0)$ & $5 / 279$ & $(1.8)$ & $2 / 279$ & $(0.7)$ & & \\
\hline
\end{tabular}

Table 1. Summary results of the detection of Toxoplasma gondii DNA in vegetable samples collected from open markets located in Xining City, Qinghai Province, P.R. China using real-time PCR.

of positive samples was noted during winter and early spring season. Presence of parasite was confirmed in only $3 / 100(3 \%)$ of vegetable samples collected in January and none of the samples collected in March 0/35 (0\%) (Table 1). Chi-square test, however didn't show statistical dependence between number of positive samples and month $\chi^{2}=2.08(\mathrm{p}=0.55)$. Frequency of positive vegetable samples collected during particular sampling months against the total number of vegetable samples collected in this study $(\mathrm{n}=279)$ was as follows: $5 / 279(1.8 \%), 3 / 279$ (1.1\%) and 2/279 (0.7\%) for July, January and August respectively (Table 1$)$.

Results of quantitative real-time PCR enabled the calculation of equivalent of $T$. gondii oocysts present in positive vegetable samples, in the final suspension obtained after flocculation (Table 2). The approximate level of contamination of positive vegetables samples ranged between less than one and $27000 \mathrm{~T}$. gondii oocysts per sample, with majority not exceeding several oocysts per sample (Table 2) (detailed information about qPCR including standard curve and positive samples is available in Supplementary Tables S1 and S2). 
(a)
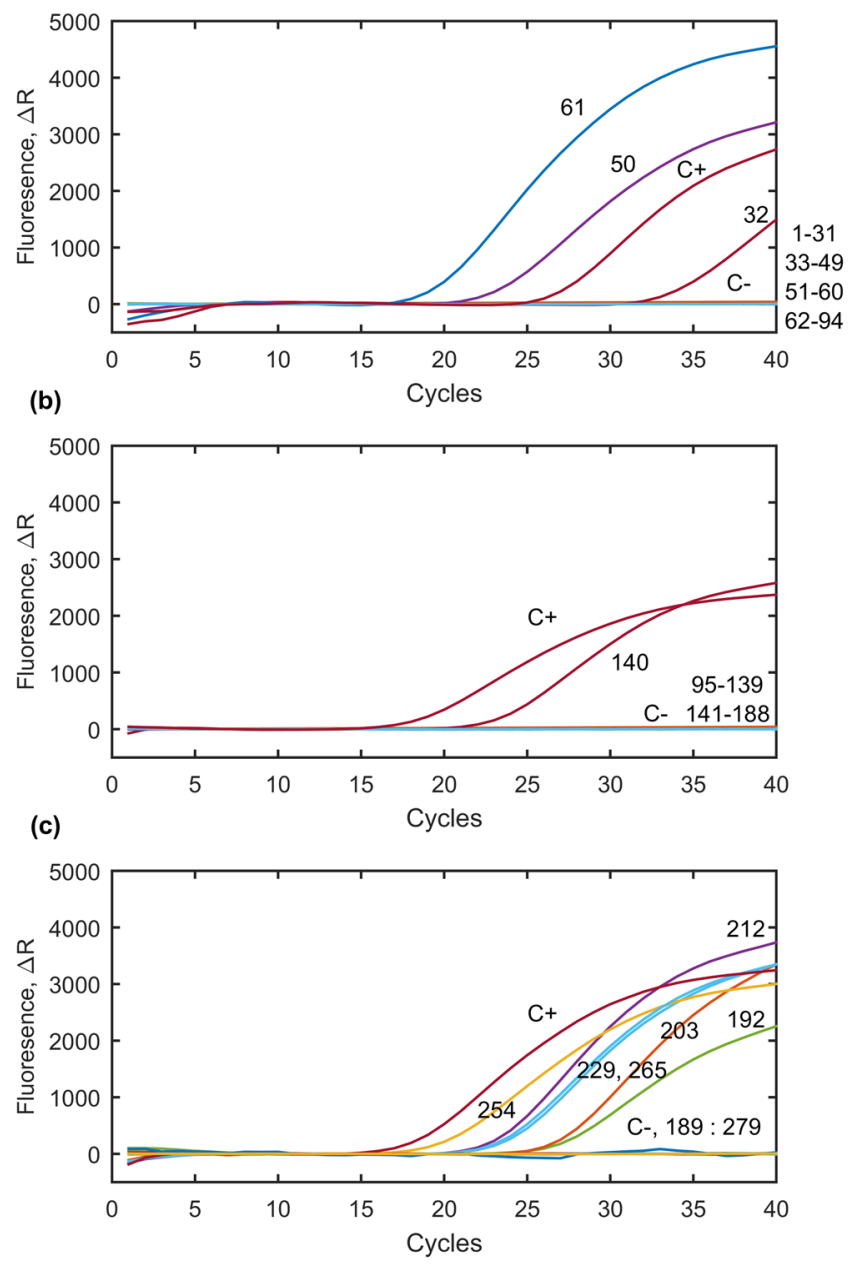

Figure 2. Results of T. gondii DNA detection in vegetable samples collected from the area of Xining City, Qinghai Province, P.R. China using real-time PCR. C+ refers to positive control; C- refers to negative control; numbers of lines correspond to numbers of templates as follows 32, 50, 61, 140, 192, 203, 212, 229, 254, 265 positive samples and 1-31, 33-49,51-60, 62-94, 95-139, 141-188, 189-191, 193-202, 204-211, 213-228, 230253, 255-264, 267-279 negative samples.

\section{Discussion}

In the present study we successfully detected Toxoplasma DNA in fresh vegetable samples collected from local open markets located in the Xining City, the capital of Qinghai province in China. To the best of our knowledge, this is the first investigation describing T. gondii detection in vegetable samples collected from territory of P.R. China using sensitive molecular tools. T. gondii DNA was detected in ten out of 279 tested samples. The results of our study confirmed that fresh vegetables available in this part of China were contaminated with T. gondii and they may pose a potential threat for public safety, particularly, people consuming them raw and unwashed.

Contamination of vegetables goes hand in hand with contamination of surrounding environment, mainly soil and water, and the driving force behind it is felid activity. While there is an absence of studies regarding $T$. gondii presence in water, Toxoplasma has been detected in soil in different parts of China, both in urban ${ }^{72,74,75}$ and agricultural areas ${ }^{71,73,74}$. These studies included Qinghai and Gansu provinces in the north-western part, Harbin and Wuhan in the centre and Nanjing in the east and all of them showed over $10 \%$ of contamination rate, in some cases $30 \%{ }^{71-75}$. Most probably stray cats play a pivotal role in epidemiology of toxoplasmosis; they roam freely and may void invasive oocysts of the parasite to the environment with faeces. It is possible that these animals may reach areas where fruit and vegetables are growing and contaminate it with the Toxoplasma oocysts. In China, epidemiological surveys have been conducted regarding prevalence of T. gondii in cats; a systematic review of publications between 1995 and 2016 included 38 studies and estimated the average infection rate in 20\%, and seroprevalence in stray cats was significantly higher than in pet cats $^{76}$. Investigations performed in north-western China in Lanzhou City, Gansu Province showed 21.3\% examined cats infected including 15.6\% and 45.2\% for household and stray cats respectively ${ }^{77}$. In QTP, types of Felidae have also been speculated as a potential source of T. gondii, such as Pallas' cat (Otocolobus manul) and Chinese mountain cat (Felis bieti), both species populating the plateau in high numbers ${ }^{78}$. Therefore, the contaminating agent and background contamination are well 


\begin{tabular}{|l|l|l|l|l|l|l|}
\hline Template No & Type of sample & $\begin{array}{l}\text { Real-time } \\
\text { PCR result }\end{array}$ & N & OCS & CCS & $\begin{array}{l}\text { T.gondii } \\
\text { genotype }\end{array}$ \\
\hline 32 & Pak choi (Brassica rapa subsp. chinensis) & $3 / 3$ & $4.94 \mathrm{e}+001$ & 1.7 & 13.6 & I \\
\hline 50 & Red cabbage (Brassica oleracea) & $3 / 3$ & $6.99 \mathrm{e}+002$ & 25 & 200 & II \\
\hline 61 & Rape (Brassica napus) & $3 / 3$ & $7.74 \mathrm{e}+005$ & 27640 & 221120 & II \\
\hline 140 & Spinach (Spinacia oleracea) & $3 / 3$ & $9.56 \mathrm{e}+004$ & 340 & 2730 & I \\
\hline 192 & Lettuce (Lactuca sativa) & $3 / 3$ & $9.66 \mathrm{e}+000$ & 0.3 & 2.76 & I \\
\hline 203 & Lettuce (Lactuca sativa) & $3 / 3$ & $7.00 \mathrm{e}+002$ & 25 & 200 & I \\
\hline 212 & Lettuce (Lactuca sativa) & $3 / 3$ & $7.56 \mathrm{e}+005$ & 27000 & 432000 & I \\
\hline 229 & Spinach (Spinacia oleracea) & $3 / 3$ & $6.64 \mathrm{e}+001$ & 2.4 & 19.2 & I \\
\hline 254 & Lettuce (Lactuca sativa) & $3 / 3$ & $1.29 \mathrm{e}+002$ & 4.6 & 36.8 & II \\
\hline 265 & Lettuce (Lactuca sativa) & $3 / 3$ & $5.30 \mathrm{e}+000$ & 0.18 & 1.44 & I \\
\hline
\end{tabular}

Table 2. Characteristics of positive vegetable samples collected from open markets in the Xining City, Qinghai Province, P.R. China, regarding detection (reproducibility of real-time PCR results), quantification, and genotyping of T. gondii. (3/3) three positive results obtained per three repeats of real-time PCR. N - initial copy number (number of copies of T. gondii B1 gene) present in washings of investigated vegetable sample after flocculation, calculated using qPCR. OCS - oocyst charge of the sample - equivalent of number of $T$. gondii oocysts which could be present in vegetable samples calculated based on initial copy number (N). CCS - calculated equivalent of initial number of $T$. gondii cells (sporozoites) present in positive vegetable samples (OCS x 8, one oocysts consist of two sporocysts filled with four sporozoites each).

established theoretically. Data from QTP and other parts of China, including provinces from which vegetables are transported to the Qinghai Province, indicate presence of Toxoplasma in the environment.

Presence of T. gondii DNA has been confirmed in different type of vegetable samples investigated in this study including lettuce, spinach, pak choi, rape and red cabbage samples. We have noticed differences in number of positive vegetable samples between seasons in which they were collected. Toxoplasma DNA was more frequently found in samples collected during summer months in comparison to winter and early spring. Different factors may influence this situation, such as felid activity, water or aeolian erosion and agricultural practice. Vegetables may originate from greenhouses or farmlands; when they are grown on open fields they are exposed to the rain and wind that enable transportation of soil particles and oocysts from soil surface on the vegetables. The irrigation practice may provide a similar mechanism of transportation, from soil to vegetables, or become the contamination agent in cases where the irrigational water is contaminated. Moreover, open fields are accessible to animals including felids that may excrete the oocysts of T. gondii and therefore, we have found higher number of positive samples among collected during warm months when animal activity is rising and the use of greenhouses is reduced.

The level of contamination of collected samples in this study was 3.6\%, which is lower than what has been previously reported in other countries ${ }^{28,29}$. These studies included collection of vegetables covering a spectrum of agricultural practices, logistics and distribution as well as environmental conditions. The study conducted in Paraná, Brazil, with a tropical climate, showed $3.8 \%$ of vegetable samples collected from sales outlets and production sites positive to Toxoplasma ${ }^{29}$. In the same area, vegetables sold in community fairs, producers' market and generally open markets, from local producers with the corresponding logistics, and showed 9.5\% samples contaminated $^{26}$. The study which was conducted in northern Poland, an area with oceanic climate, included fruit and vegetables from open markets, from direct producers but also from greengrocers and supermarkets, while the products originated from the general area of sampling; the overall rate of contaminated samples was $9.7 \%{ }^{28}$. On the other hand, a broad study in major Canadian cities, under completely different conditions, showed quite lower contamination level $(0.26 \%)^{27}$; it regarded imported pre-packaged or bulk green vegetables from USA and Mexico, with the corresponding logistics. In the aforementioned study in Poland, samples taken from supermarkets, where washing and sanitizing methods may have been applied, showed no contamination ${ }^{28}$. Our study regards, on one hand vegetables supplied in open markets, but on the other they are transported hundreds of kilometres away from the cultivation site and provided through a centralised system to the small sellers in these markets, constituting a combination of the previous examples. Therefore they may have more sophisticated packaging than in the cases of direct produce or decentralised distribution, and possibly some form of washing or sanitizing for a part of them.

The primary contamination of vegetables during cultivation has been established in a number of cases ${ }^{26,28}$. It should be emphasized that while comparing data from cited studies, different factors that could influence the results should be taken under consideration such as limitations of recovery, concentration and detection methods used, as well as the environmental contamination background of the investigated region, we may also assume that the handling of vegetables after their collection influences the contamination level and the threat for the public. Nevertheless, a coordinated screening of soil, vegetables and the end product at the hands of the consumer should be organised to properly assess the risk at each level of production.

Genotyping of positive samples collected in this study indicated that T. gondii isolates represent type I (eight samples) and II (two samples). Although, T. gondii - Chinese 1 genotype is widely prevalent in China with a rising gradient from west to east, in the northwest of China where Qinghai is situated, the predominating genotypes are type II and I followed by Chinese $1^{35}$. Our results follow a similar pattern, since vegetables may originate from the north-western provinces, Qinghai, Gansu and Shaanxi, or Henan, Shandong and Yunnan, where Toxoplasma 
- type I genotype is common ${ }^{35}$ (Fig. 1). The study of agricultural soil contamination with Toxoplasma could help establish a hypothesis, but such studies in China have not included genotyping ${ }^{71,73,74}$. Hence, we assume that the localities where the particular vegetables were cultivated were contaminated with the aforementioned genotypes.

Additionally, an equivalent of the approximate oocyst charge using qPCR was established to a mean level of positive samples. The order of magnitude of the number of oocysts that might be present in positive samples ranged from one to $10^{4}$. For half of samples number of oocysts was below 10, and only two of them were highly contaminated. Actual contamination, however, could be even higher than demonstrated due to loss of material during the recovery process. Although the infective dose (number of oocysts) responsible for the development of infection in humans is unknown, the results indicate that transmission of the parasite to Chinese citizens by consumption of such vegetables raw and unwashed should be taken into consideration. A similar study performed in Poland showed that number of T. gondii oocysts present in vegetable samples collected from open markets and greengrocers was less than ten ${ }^{28}$.

Although, the morphological integrity, viability, biological activity or virulence of Toxoplasma isolates was not investigated in this study, and consequently their ability to infect humans and/or animals remains unknown, the detection of T. gondii DNA and evaluation the probable intensity of contamination of with T. gondii oocysts in vegetable samples is clear evidence for the presence of the parasite in the food chain and indicates a potential risk for humans.

Consumption of unwashed vegetables and fruits contaminated with Toxoplasma has been ranked amongst the highest risk factors for toxoplasmosis in Norway, due to the regularity these are consumed ${ }^{70}$. In parts of China, poor eating habits like neglect of hand washing before meal or dinner preparation has been indicated as a risk factor of toxoplasmosis infection ${ }^{67}$. In areas with high risks for public health, however, where traditional communal ties have not been ruptured, society, through its historical experience, has adopted countermeasures to alleviate such problems. In the case of Xining City, the general contamination background in QTP regarding parasites, which includes other dangerous parasites such as Echinococcus spp. and other Taeniidae, has forced the society to adapt by customizing its habits accordingly, like boiling water and vegetables before consumption. This is also a most probable reason why QTP and China in general, displays lower toxoplasmosis levels than the world average. Nevertheless, societal changes, like urbanization or import of different customs, like society in QTP is experiencing now, may rupture such ties, and this is when awareness and education helps in the prevention of threats that were historically managed, and general improvement of public health. Hence, protection against toxoplasmosis and other public health threats can be achieved by adoption of hygiene measures and practices in open markets, as well as sanitary regulations and best practices for larger units and centralised distribution centres, like warehouses and supermarkets.

Considering the possibility of working with contaminated vegetables and fruit as a risk factor of toxoplasmosis, a comparison with the meat industry can be performed. A study in Mexico has concluded that toxoplasmosis is not associated with handling unwashed and raw vegetables in areas with relatively low prevalence of Toxoplasma like in China ${ }^{79}$. Therefore, we can assume that the relatively low prevalence rate in vegetables and the occupational characteristics, regarding the handling of vegetables, do not constitute an additional risk for the workers in this sector, in contrast with other agro-industries like the meat producing. This is in contrast with the meat processing and dairy industry, where Toxoplasma has been established as a potential occupational risk factor $^{80-82}$, accounting for the differences during the production processes and the conditions workers are exposed. However, more data, from different provinces of China, focused on the presence of Toxoplasma in vegetables is needed to draw unequivocal conclusions.

\section{Conclusions}

Toxoplasmosis is a persistent problem in China. In this study, we report contamination of vegetable samples available in local open market in Xining City in the Qinghai-Tibet Plateau, in China, with T. gondii. The detection of T. gondii DNA in vegetable samples is evidence of the presence of the parasite in the agricultural environment and its persistence through multiple stages in the food sector, indicating a potential risk for humans. Therefore, results of our study call for more concentrated screening of the environmental matrices, soil, vegetables and the different production stage to establish the transmission routes, and the level of risk to contract toxoplasmosis through contact with contaminated vegetables. Furthermore, revision and adoption of food safety practices in order to prevent $T$. gondii from reaching the consumers through the food chain, in this and other parts of China.

\section{Methods}

Recovery and concentration of oocysts from vegetable samples. At first vegetables were rinsed thoroughly. In order to concentrate and recover Toxoplasma gondii oocysts from washing suspensions, $\mathrm{Al}_{2}\left(\mathrm{SO}_{4}\right)_{3}$ flocculation methodology was employed ${ }^{83}$. Finally, the suspension obtained was preserved at $-20^{\circ} \mathrm{C}$ for further analysis.

DNA extraction. Prior to DNA extraction, the material obtained from vegetable samples was prepared using ten freeze-thaw cycles (using liquid nitrogen and a water bath) to destroy the walls of the oocysts and improve the efficiency of DNA extraction. Afterwards, DNA extraction was performed using a commercial TIANamp Micro DNA Kit (DP 316) (Tiangen Biotech, Beijing, China) according to the manufacturer's instructions. The DNA was then stored at $-20^{\circ} \mathrm{C}$.

Specific detection of $T$. gondii DNA by real-time PCR. For specific detection of Toxoplasma gondii DNA real-time PCR assay based on T. gondii B1 gene ${ }^{84}$ was used. Each vegetable sample was examined three times. Briefly, the amplification reaction mixture consisted of $12.5 \mu \mathrm{L}$ of Real-Time $2 \mathrm{x}$ HS-PCR Master Mix Probe 


\begin{tabular}{|c|c|c|c|c|c|}
\hline Marker & & PCR primers $\left(5^{\prime}-3^{\prime}\right)$ & Size (bp) & Restriction enzymes & Enzyme digestion conditions \\
\hline SAG1 ${ }^{87}$ & $\begin{array}{l}\text { SAG1 Ex F: } \\
\text { SAG1 Ex R: } \\
\text { SAG1 In F: } \\
\text { SAG1 In R: }\end{array}$ & $\begin{array}{l}\text { GTTCTAACCACGCACCCTGAG } \\
\text { AAGAGTGGGAGGCTCTGTGA } \\
\text { CAATGTGCACCTGTAGGAAGC } \\
\text { GTGGTTCTCCGTCGGTGTGAG }\end{array}$ & 390 & $\begin{array}{l}\text { Cfr13I + BfoI, } \\
\text { Thermo Scientific } \\
\text { (double digest) }\end{array}$ & $37^{\circ} \mathrm{C} 1 \mathrm{~h}$ \\
\hline $\mathrm{SAG} 2^{86}$ & $\begin{array}{l}\text { SAG2 Ex F: } \\
\text { SAG2 Ex R: } \\
\text { SAG2 In F: } \\
\text { SAG2 In R: }\end{array}$ & $\begin{array}{l}\text { GGAACGCGAACAATGAGTTT } \\
\text { GCACTGTTGTCCAGGGTTTT } \\
\text { ACCCATCTGCGAAGAAAACG } \\
\text { ATTTCGACCAGCGGGAGCAC }\end{array}$ & 546 & $\begin{array}{l}\text { HinfI + TaqI, } \\
\text { Thermo scientific }\end{array}$ & $37^{\circ} \mathrm{C} 1 \mathrm{~h}+65^{\circ} \mathrm{C} 1 \mathrm{~h}$ \\
\hline $\mathrm{SAG}^{87}$ & $\begin{array}{l}\text { SAG3 Ex F: } \\
\text { SAG3 Ex R: } \\
\text { SAG3 In F: } \\
\text { SAG3 In R: }\end{array}$ & $\begin{array}{l}\text { CAACTCTCACCATTCCACCC } \\
\text { GCGCGTTGTTAGACAAGACA } \\
\text { TCTTGTCGGGTGTTCACTCA } \\
\text { CACAAGGAGACCGAGAAGGA }\end{array}$ & 311 & $\begin{array}{l}\text { BcnI, } \\
\text { Thermo Scientific }\end{array}$ & $37^{\circ} \mathrm{C} 1 \mathrm{~h}$ \\
\hline c $22-8^{86}$ & $\begin{array}{l}\text { C22-8 Ex F: } \\
\text { C22-8 Ex R: } \\
\text { C22-8 In F: } \\
\text { C22-8 In R: }\end{array}$ & $\begin{array}{l}\text { TGATGCATCCATGCGTTTAT } \\
\text { CCTCCACTTCTTCGGTCTCA } \\
\text { TCTCTCTACGTGGACGCC } \\
\text { AGGTGCTTGGATATTCGC }\end{array}$ & 521 & $\begin{array}{l}\text { Alw26I + MboII, } \\
\text { Thermo Scientific } \\
\text { (double digest) }\end{array}$ & $37^{\circ} \mathrm{C} 1 \mathrm{~h}+55^{\circ} \mathrm{C} 1 \mathrm{~h}$ \\
\hline c $22-9^{86}$ & $\begin{array}{l}\text { C29-2 Ex F: } \\
\text { C29-2 Ex R: } \\
\text { C29-2 In F: } \\
\text { C29-2 In R: }\end{array}$ & $\begin{array}{l}\text { ACCCACTGAGCGAAAAGAAA } \\
\text { AGGGTCTCTTGCGCATACAT } \\
\text { AGTTCTGCAGAGTGTCGC } \\
\text { TGTCTAGGAAAGAGGCGC } \\
\end{array}$ & 446 & $\begin{array}{l}\text { TaiI + RsaI, } \\
\text { Thermo Scientific } \\
\text { (double digest) }\end{array}$ & $37^{\circ} \mathrm{C} 1 \mathrm{~h}$ \\
\hline $\mathrm{L} 358^{86}$ & $\begin{array}{l}\text { L358 Ex F: } \\
\text { L358 Ex R: } \\
\text { L358 In F: } \\
\text { L358 In R: }\end{array}$ & $\begin{array}{l}\text { TCTCTCGACTTCGCCTCTTC } \\
\text { GCAATTTCCTCGAAGACAGG } \\
\text { AGGAGGCGTAGCGCAAGT } \\
\text { CCCTCTGGCTGCAGTGCT }\end{array}$ & 418 & $\begin{array}{l}\text { BsuRI + Hin1II, } \\
\text { Thermo Scientific } \\
\text { (double digest) }\end{array}$ & $37^{\circ} \mathrm{C} 1 \mathrm{~h}$ \\
\hline BTUB $^{86}$ & $\begin{array}{l}\text { BTUB Ex F: } \\
\text { BTUB Ex R: } \\
\text { BTUB In F: } \\
\text { BTUB In R: }\end{array}$ & $\begin{array}{l}\text { TCCAAAATGAGAGAAATCGT } \\
\text { AAATTGAAATGACGGAAGAA } \\
\text { GAGGTCATCTCGGACGAACA } \\
\text { TTGTAGGAACACCCGGACGC }\end{array}$ & 411 & $\begin{array}{l}\text { Bsh1285I + TaqI, } \\
\text { Thermo Scientific } \\
\text { (double digest) }\end{array}$ & $65^{\circ} \mathrm{C} 1 \mathrm{~h}$ \\
\hline $\mathrm{PK} 1^{86}$ & $\begin{array}{l}\text { L358 Ex F: } \\
\text { L358 Ex R: } \\
\text { L358 In F: } \\
\text { L358 In R: }\end{array}$ & $\begin{array}{l}\text { TCTCTCGACTTCGCCTCTTC } \\
\text { GCAATTTCCTCGAAGACAGG } \\
\text { AGGAGGCGTAGCGCAAGT } \\
\text { CCCTCTGGCTGCAGTGCT }\end{array}$ & 903 & $\begin{array}{l}\text { Eco88I + RsaI, } \\
\text { Thermo Scientific } \\
\text { (double digest) }\end{array}$ & $37^{\circ} \mathrm{C} 1 \mathrm{~h}$ \\
\hline GRA $6^{86}$ & $\begin{array}{l}\text { GRA6 Ex F: } \\
\text { GRAG Ex R: } \\
\text { GRA6 In F: } \\
\text { GRA } 6 \text { In R: }\end{array}$ & $\begin{array}{l}\text { ATTTGTGTTTCCGAGCAGGT } \\
\text { GCACCTTCGCTTGTGGTT } \\
\text { TTTCCGAGCAGGTGACCT } \\
\text { TCGCCGAAGAGTTGACATAG }\end{array}$ & 344 & $\begin{array}{l}\text { TrulI, } \\
\text { Thermo Scientific }\end{array}$ & $37^{\circ} \mathrm{C} 1 \mathrm{~h}$ \\
\hline $\mathrm{Apico}^{86}$ & $\begin{array}{l}\text { APICO Ex F: } \\
\text { APICO Ex R: } \\
\text { APICO In F: } \\
\text { APICO In R: }\end{array}$ & $\begin{array}{l}\text { TGGTTTTAACCCTAGATTGTGG } \\
\text { AAACGGAATTAATGAGATTTGAA } \\
\text { GCAAATTCTTGAATTCTCAGTT } \\
\text { GGGATTCGAACCCTTGATA }\end{array}$ & 640 & $\begin{array}{l}\text { AflII + DdeI, } \\
\text { Thermo Scientific } \\
\text { (double digest) }\end{array}$ & $37^{\circ} \mathrm{C} 1 \mathrm{~h}$ \\
\hline
\end{tabular}

Table 3. Summary of primers, enzymes and conditions used for multiplex multilocus nested PCR-RFLP typing of T. gondii isolates.

(A\&A Biotechnology, Gdynia, Poland), $400 \mathrm{nM}$ of each primer (Genewiz SZ, Suzhou, China), $80 \mathrm{nM}$ of TaqMan probe (Genewiz SZ, Suzhou, China), and $5 \mu \mathrm{L}$ of template DNA in a $25 \mu \mathrm{L}$ reaction volume. Amplification was performed with an initial polymerase activation step $\left(10 \mathrm{~min}\right.$ at $\left.95^{\circ} \mathrm{C}\right)$, followed by 40 cycles of denaturation $(15 \mathrm{~s}$ at $\left.95^{\circ} \mathrm{C}\right)$ and hybridisation/extension $\left(1 \mathrm{~min}\right.$ at $\left.60^{\circ} \mathrm{C}\right)$ in a AriaMx Real-time PCR thermocycler, Agilent). PCR products were analysed using AriaMx Real-time PCR System Software. The cycle threshold (CT) value, determining the cycle number at which the reporter's fluorescence exceeds the threshold value, was recorded. A sample was considered positive if the CT value was $<40$.

All PCR experiments were performed including T. gondii positive controls to ensure the correct functionality of the reaction, as well as negative controls to ensure that no PCR component had been contaminated. The DNA isolated from tachyzoites of parasite (the Toxoplasma gondii $\mathrm{RH}$ strain), obtained from the National Institute of Hygiene, Poland was used as positive control in the performed experiments.

Additionally, samples were retested for the presence of PCR inhibitors by mixing $4 \mu \mathrm{L}$ of DNA template and $1 \mu \mathrm{L}$ of internal positive control (IPC) (more details concerning the IPC used are available in Supplementary information). Comparison of results of amplification (Cq values) obtained for samples containing combination of IPC and template DNA with IPC alone allowed estimation of potential interference.

Sequencing. The final PCR products from the positive samples were sequenced. Both forward and reverse orientation cycle sequencing was performed using the amplification primers. The sequences obtained were then analysed using GeneStudio ${ }^{\text {TM }}$ Professional (GeneStudio, Inc., USA) and ChromasDNA sequencing software.

Genotyping. T. gondii genotypes were determined using multilocus PCR-RFLP assay with selected genetic markers: SAG1, SAG2, SAG3, BTUB, GRA6, c22-8, c29-2, L358, PK1 and Apico ${ }^{19,85,86}$. The set of reaction included nested PCR and restriction analysis of amplified products.

Amplification of genetic markers using nested PCR. The $1^{\text {st }}$ step of nested PCR was performed using set of external primers (Table 3) in a $25 \mu \mathrm{L}$ reaction volume and the amplification reaction mixture consisted of $12.5 \mu \mathrm{L}$ of the standard and ready-to-use PCR mixture 2xPCR Mix Plus High GC (A\&A Biotechnology, Poland) containing recombinant Taq polymerase, PCR buffer, magnesium chloride, nucleotides, stabilisers, and gel loading 


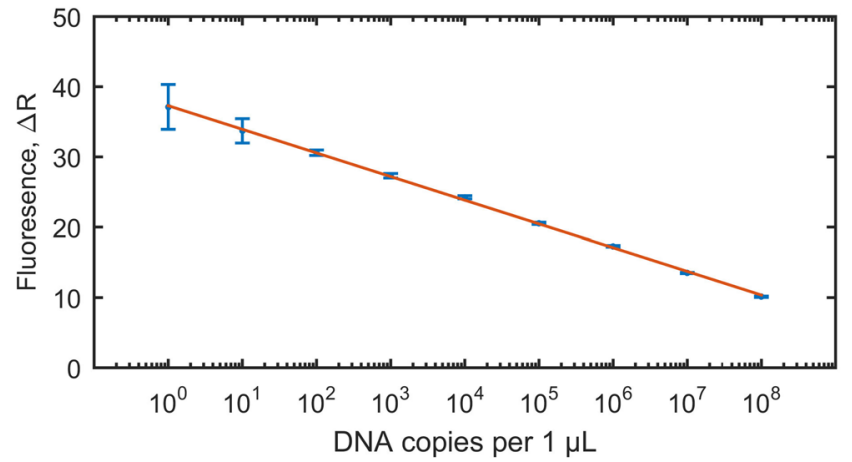

Figure 3. Standard curve, generated based on amplification of the three series of eight dilutions of standard DNA in the range from one to $10^{8}$ DNA copies per one $\mu \mathrm{L}$, with marked standard deviations of $\mathrm{Cq}(\Delta \mathrm{R})$ values obtained for standard DNA triplicates. Efficiency $\mathrm{E}[\%]=98$; Slope, $\mathrm{S}=-3.37$; Y intercept $\mathrm{y}_{\text {int }}=37.32$, Coefficient of determination, $\mathrm{R}^{2}=0.99$. The standard curve served for quantification of initial copy numbers of T. gondii B1 gene in investigated vegetable samples collected from the open markets located in Xining City, Qinghai Province, P.R. China.

buffer, $200 \mathrm{nM}$ of each forward and reverse primer (Genewiz SZ, Suzhou, China), and $2 \mu \mathrm{L}$ of template DNA. Amplifications were performed with an initial polymerase activation step $\left(5 \mathrm{~min}\right.$ at $\left.95^{\circ} \mathrm{C}\right)$, followed by 35 cycles of denaturation $\left(30 \mathrm{~s}\right.$ at $\left.94^{\circ} \mathrm{C}\right)$, primers annealing $\left(1 \mathrm{~min}\right.$ at $\left.55^{\circ} \mathrm{C}\right)$, strand extension $\left(2 \mathrm{~min} \mathrm{~s}\right.$ at $\left.72^{\circ} \mathrm{C}\right)$, and final extension $\left(7 \mathrm{~min}\right.$ at $\left.72^{\circ} \mathrm{C}\right)$. The $2^{\text {nd }}$ step of nested PCR reactions were performed using internal set of primers (Table 3) under following amplification reaction mixture conditions: $12.5 \mu \mathrm{L}$ of the standard and ready-to-use PCR mixture 2xPCR Mix Plus High GC (A\&A Biotechnology, Poland), $400 \mathrm{nM}$ of each primer (Genewiz SZ, Suzhou, China), and $2 \mu \mathrm{L}$ of template DNA in a $25-\mu \mathrm{L}$ reaction volume. Amplifications were performed according to the same protocol as in the first reaction, with the exception that annealing temperature was $60^{\circ} \mathrm{C}$.

Restriction analysis of nested PCR products. In order to perform restriction analysis $10 \mu \mathrm{L}$ of PCR product were mixed with $2 \mu \mathrm{L}$ of $10 \mathrm{x}$ digestive buffer and $1 \mathrm{U}$ of restriction enzyme (each of the two restriction enzymes in case of double digestion) (Thermo Scientific, USA). The reaction was carried out according to manufacturer's instruction. RFLP products were analysed using a WD-9413B gel imaging analysis system (Beijing Liuyi Biotechnology, China) following electrophoresis on a 3\% gel agarose (Biowest Regular Agarose G-10, Gene Company) stained with ExRed nucleic acid electrophoresis dye (Beijing Zoman Biotechnology, China).

Determination of initial copy numbers of T. gondii DNA using qPCR. In order to determine the initial copy number of the detected T. gondii DNA, each positive sample was tested with qPCR based on a standard curve. The standard template was generated by cloning the insert gene (a fragment of the B1 gene amplified by PCR using the set of primers described above) into a plasmid. To generate the standard curve, three series of nine dilutions of standard DNA in the range from one to $10^{8} \mathrm{DNA}$ copies per one $\mu \mathrm{L}$ were prepared (Fig. 3). Following amplification of the standard dilution series, the standard curve was obtained by plotting the log of the initial template copy number against the CT value generated from each dilution. Amplification of the standard dilution series and of the DNA isolated from vegetable samples was run on the same plate. Comparing the CT values of the unknown samples with the standard curve thus enabled the quantification of initial copy numbers.

Initial copy numbers of $T$. gondii DNA were used to calculate equivalent of $T$. gondii dispersive forms that might be present in the examined samples after flocculation (recovery procedure). According to our previous experiments, using real-time PCR, it is possible to detect single T. gondii oocyst in water suspension ${ }^{13}$. Thus, the number of $T$. gondii oocysts (oocyst charge of the sample) was estimated using following formula: OCS $=\frac{N}{35} \times \frac{1}{A} \times B$ where: OCS is the oocyst charge of the sample; $\mathrm{N}$ is the initial copy number determined using qPCR (per amount of DNA template taken for PCR); 35 is the number of copies of the B1 gene per one $T$. gondii cell; $A=8$, the number of T. gondii sporozoites per one oocyst; $\mathrm{B}$ is the multiplication factor referring to a total amount of DNA extracted from investigated sample.

Statistical analysis. In order to investigate the correlation between $T$. gondii presence in investigated vegetable samples and sampling period statistical analysis was performed using the Pearson chi-square test $\left(\chi^{2}\right)$. Calculations were performed using MATLAB 2015a.

\section{Data availability}

All data generated or analysed during this study are included in this published article.

Received: 25 July 2019; Accepted: 24 October 2019;

Published online: 26 November 2019 


\section{References}

1. Montoya, J. G. \& Liesenfeld, O. Toxoplasmosis. Lancet 363, 1965-1976 (2004).

2. Wong, S.-Y. \& Remington, J. S. Biology of Toxoplasma gondii. AIDS 7, 299-316 (1993).

3. Joynson, D. H. M. \& Wreghitt, T. G. Toxoplasmosis: A comprehensive clinical guide. xiv, 395 (Cambridge University Press, 2001).

4. Luft, B. J. \& Remington, J. S. Toxoplasmic encephalitis in AIDS. Clinical Infectious Diseases 15, 211-222 (1992).

5. Beazley, D. M. \& Egerman, R. S. Toxoplasmosis. Seminars in Perinatology 22, 332-338 (1998).

6. Wong, S.-Y. \& Remington, J. S. Toxoplasmosis in pregnancy. Clinical Infectious Diseases 18, 853-862 (1994).

7. Benenson, M., Takafuji, E. T., Lemon, S. M., Greenup, R. L. \& Sulzer, A. J. Oocyst-transmitted toxoplasmosis associated with ingestion of contaminated water. The New England Journal of Medicine 307, 666-669 (1982).

8. Dumètre, A. \& Dardé, M.-L. How to detect Toxoplasma gondii oocysts in environmental samples? FEMS Microbiology Reviews 27, 651-661 (2003)

9. Remington, J. S., McLeod, R., Thulliez, P. \& Desmonts, G. Chapter 31: Toxoplasmosis. In Infectious diseases of the fetus and newborn (eds Remington, J. S., Klein, J. O., Baker, C. J. \& Wilson, C. B.) 947-1092 (Saunders, 2006).

10. Robert-Gangneux, F. \& Dardé, M.-L. Epidemiology of and diagnostic strategies for toxoplasmosis. Clinical Microbiology Reviews 25, 264-296 (2012).

11. Weinman, D. \& Chandler, A. H. Toxoplasmosis in man and swine - An investigation of the possible relationship. Journal of the American Medical Association 161, 229-232 (1956).

12. Lass, A. et al. Detection of Toxoplasma gondii oocysts in environmental soil samples using molecular methods. European Journal of Clinical Microbiology \& Infectious Diseases 28, 599-605 (2009).

13. Lass, A., Szostakowska, B., Korzeniewski, K. \& Karanis, P. The first detection of Toxoplasma gondii DNA in environmental air samples using gelatine filters, real-time PCR and loop-mediated isothermal (LAMP) assays: qualitative and quantitative analysis. Parasitology 144, 1791-1801 (2017).

14. Sroka, J., Wójcik-Fatla, A. \& Dutkiewicz, J. Occurrence of Toxoplasma gondii in water from wells located on farms. Annals of Agricultural and Environmental Medicine 13, 169-175 (2006).

15. Gallas-Lindemann, C., Sotiriadou, I., Mahmoodi, M. R. \& Karanis, P. Detection of Toxoplasma gondii oocysts in different water resources by Loop Mediated Isothermal Amplification (LAMP). Acta Tropica 125, 231-236 (2013).

16. Simon, J. A. et al. Spatial distribution of soil contaminated with Toxoplasma gondii oocysts in relation to the distribution and use of domestic cat defecation sites on dairy farms. International Journal for Parasitology 47, 357-367 (2017).

17. Villena, I. et al. Evaluation of a strategy for Toxoplasma gondii oocyst detection in water. Applied and Environmental Microbiology 70, 4035-4039 (2004).

18. Wells, B. et al. Molecular detection of Toxoplasma gondii in water samples from Scotland and a comparison between the 529bp realtime PCR and ITS1 nested PCR. Water Research 87, 175-181 (2015).

19. Ferreira, I. M. R. et al. Toxoplasma gondii isolates: Multilocus RFLP-PCR genotyping from human patients in Sao Paulo State, Brazil identified distinct genotypes. Experimental Parasitology 129, 190-195 (2011).

20. Moura, L. D. et al. Waterborne toxoplasmosis, Brazil, from field to gene. Emerging Infectious Diseases 12, 326-329 (2006).

21. Verant, M. L. et al. Attempted detection of Toxoplasma gondii oocysts in environmental waters using a simple approach to evaluate the potential for waterborne transmission in the Galápagos Islands, Ecuador. EcoHealth 11, 207-214 (2014).

22. Mahmoudi, M. R., Kazemi, B., Haghighi, A. \& Karanis, P. Detection of Acanthamoeba and Toxoplasma in river water samples by molecular methods in Iran. Iranian Journal of Parasitology 10, 250-257 (2015).

23. Saki, J., Khademvatan, S., Yousefi, E., Tavalla, M. \& Abdizadeh, R. Detection and genotyping of Toxoplasma gondii isolated from soil in Ahvaz, southwest of Iran. Journal of Parasitic Diseases 41, 202-205 (2017).

24. Koloren, Z. Sensitive and cost-effective detection of Toxoplasma gondii in water supplies of the Black Sea in Turkey by LoopMediated Isothermal Amplification (LAMP). Biotechnology \& Biotechnological Equipment 27, 3543-3546 (2013).

25. Kniel, K. E. et al. Examination of attachment and survival of Toxoplasma gondii oocysts on raspberries and blueberries. The Journal of Parasitology 88, 790-793 (2002).

26. Ferreira, F. P. et al. The effect of water source and soil supplementation on parasite contamination in organic vegetable gardens. Revista Brasileira e Parasitologia Veterinária 27, 327-337 (2018).

27. Lalonde, L. F. \& Gajadhar, A. A. Detection of Cyclospora cayetanensis, Cryptosporidium spp., and Toxoplasma gondii on imported leafy green vegetables in Canadian survey. Food and Waterborne. Parasitology 2, 8-14 (2016).

28. Lass, A., Pietkewicz, H., Szostakowska, B. \& Myjak, P. The first detection of Toxoplasma gondii DNA in environmental fruits and vegetables samples. European Journal of Clinical Microbiology \& Infectious Diseases 31, 1101-1108 (2012).

29. Marchioro, A. A. et al. First detection of Toxoplasma gondii DNA in the fresh leafs of vegetables in South America. Vector-Borne and Zoonotic Diseases 16, 624-626 (2016).

30. Howe, D. K. \& Sibley, L. D. Toxoplasma gondii comprises three clonal lineages: Correlation of parasite genotype with human disease. The Journal of Infectious Diseases 172, 1561-1566 (1995).

31. Khan, A. et al. Genetic analyses of atypical Toxoplasma gondii strains reveal a fourth clonal lineage in North America. International Journal for Parasitology 41, 645-655 (2011).

32. Mercier, A. et al. Additional haplogroups of Toxoplasma gondii out of Africa: Population structure and mouse-virulence of strains from Gabon. PLoS Neglected Tropical Diseases 4, e876 (2010).

33. Minot, S. et al. Admixture and recombination among Toxoplasma gondii lineages explain global genome diversity. Proceedings of the National Academy of Sciences of the United States of America 109, 13458-13463 (2012).

34. Rajendran, C., Su, C. \& Dubey, J. P. Molecular genotyping of Toxoplasma gondii from Central and South America revealed high diversity within and between populations. Infection, Genetics and Evolution 12, 359-368 (2012).

35. Chaichan, P. et al. Geographical distribution of Toxoplasma gondii genotypes in Asia: A link with neighboring continents. Infection, Genetics and Evolution 53, 227-238 (2017).

36. Chen, Z. et al. Genotyping of Toxoplasma gondii isolates from cats in different geographic regions of China. Veterinary Parasitology 183, 166-170 (2011).

37. Wang, L. et al. Genotypes and mouse virulence of Toxoplasma gondii isolates from animals and humans in China. PLoS One 8, e53483 (2013).

38. Zhou, P. et al. Genetic characterization of Toxoplasma gondii isolates from China. Parasitology International 58, 193-195 (2009).

39. Shwab, E. K. et al. Geographical patterns of Toxoplasma gondii genetic diversity revealed by multilocus PCR-RFLP genotyping. Parasitology 141, 453-461 (2014).

40. Bertranpetit, E. et al. Phylogeography of Toxoplasma gondii points to a South American origin. Infection, Genetics and Evolution 48, 150-155 (2017).

41. Li, M. et al. Phylogeny and virulence divergency analyses of Toxoplasma gondii isolates from China. Parasites \& Vectors 7,133 (2014).

42. Lorenzi, H. et al. Local admixture of amplified and diversified secreted pathogenesis determinants shapes mosaic Toxoplasma gondii genomes. Nature Communications 7, 10147 (2016).

43. Pan, M., Lyu, C., Zhao, J. \& Shen, B. Sixty years (1957-2017) of research on toxoplasmosis in China-An overview. Frontiers in Microbiology 8, 1825 (2017)

44. Gross, U. Toxoplasma gondii. 219, ix, 276 (Springer-Verlag, 1996). 
45. Lu, Y. \& Cui, J. An epidemiological survey on toxoplasmosis in 16 provinces of China. Journal of Practical Parasitic Diseases 03, 19-22 (1994)

46. CONSIHPD. A national survey on current status of the important parasitic diseases in human population. Chinese Journal of Parasitology \& Parasitic Diseases 23, 332-340 (2005).

47. Zhou, Q. et al. Seroepidemiological map of Toxoplasma gondii infection and associated risk factors in preconception period in China: A nationwide cross-sectional study. Journal of Obstetrics and Gynaecology Research 44, 1134-1139 (2018)

48. Li, H. et al. Seroepidemiology of Toxoplasma gondii infection in Bai and Han ethnic groups in southwestern China. Epidemiology \& Infection 143, 881-886 (2015).

49. Mi, X., Ba, Y. \& Wen, C. Epidemic investigation of Toxoplasma infection in pigs, cattle and sheep. Chinese. Journal of Veterinary Parasitology 15, 22-24 (2007).

50. Yin, M. et al. Seroprevalence and risk factors of Toxoplasma gondii in tibetan sheep in Gansu province, Northwestern China. BMC Veterinary Research 11, 41 (2015).

51. Ma, W. \& Ma, L. Serological investigation ot toxoplasmosis in improved cashmere goats in Haixi District of Qinghai Province. Progress in Veterinary Medicine 30, 122-124 (2009).

52. Yang, X. et al. Comparison on the serological investigation in Toxoplasma gondii infection of cashmere goats in shed-feeding and in half shed-feeding. Chinese Journal of Zoonoses 25, 822-823 (2009).

53. Zheng, B. \& Li, J. Research progress of risk factors associated with Toxoplasma gondii in pigs, cattle and chickens and their infectious status in China. China Animal Health Inspection 33, 67-70 (2016).

54. Zhou, X. et al. Seroprevalence of Toxoplasma gondii in cattle, sheep and goats in partial area of China. China Herbivore Science 34, $43-46$ (2014)

55. Sun, C., Xia, B., Zhang, L. \& Li, H. Seroepidemiology survey of Toxoplasma gondii infection in pigs in the border areas of Yunnan Province. Heilongjiang Animal Science and Veterinary Medicine 100-101, https://doi.org/10.13881/j.cnki.hljxmsy.2017.12.0278 (2018).

56. Wu, D. et al. Seroprevalence of Toxoplasma gondii antibodies from slaughter pigs in Chongqing, China. Tropical Animal Health and Production 44, 685-687 (2012).

57. Pan, Y. et al. A survey on Toxoplasma gondii infection on persons and domestic animals in Jiaodong. Shandong yixue yuan xuebao $51-53(1989)$

58. Wang, M., Ye, Q., Zhang, N. \& Zhang, D. Seroprevalence of Toxoplasma gondii infection in food-producing animals in Northwest China. Chinese Journal of Zoonoses 32, 608-612 (2016).

59. Li, Y., Li, Y. \& Zhang, M. The epidemiology of Toxoplasma gondii in retail pork in Luohe, He'nan Province. Academic Periodical of Farm Products Processing 18, 69-70 (2014).

60. Lu, L. et al. Investigation on the animal foods contaminated with parasites in markets in Huangpu District of Shanghai from 2015 to 2017. Journal of Tropical Diseases and Parasitology 16, 23-25 (2018).

61. Shi, B., Zhao, W., Sun, J., Liu, S. \& Li, K. Monitoring and analysis of food-borne parasites in freshwater products and meats in Jilin province. Journal of Food Safety \& Quality 9, 1185-1189 (2018).

62. Wang, H. et al. Prevalence and genotypes of Toxoplasma gondii in pork from retail meat stores in Eastern China. International Journal of Food Microbiology 157, 393-397 (2012).

63. Yu, L. et al. Establishment and application on a sensitive PCR assay for detection of Toxoplasma gondii in retail pork. Chinese Journal of Zoonoses 26, 895-899 (2010).

64. Zhan, T. et al. Molecular detection of Toxoplasma gondii in slaughtered and marketing pork products in large cities. Chinese Journal of Animal Infectious Diseases 24, 30-35 (2016).

65. Liu, M. \& Boireau, P. Trichinellosis in China: epidemiology and control. Trends in Parasitology 18, 553-556 (2002),

66. Fu, B., Li, G. \& Liu, X. Investigation on epidemical factors of Toxoplasma gondii infection. Chinese Journal of Schistosomiasis Control 218-220, https://doi.org/10.16250/j.32.1374.2005.03.022 (2005).

67. Fu, B., Sun, B., Li, H. \& Xue, Y. The relationship between the transmission of toxoplasmosis and sanitary habit. China Tropical. Medicine 4, 1046-1047 (2004).

68. Zhang, H. et al. Survey of Toxoplasma infection in rural area of Minfeng county, Xinjiang in 2017. Bulletin of Disease Control \& Prevention(China) 33(5-7), 26 (2018).

69. Jones, J. L. et al. Risk factors for Toxoplasma gondii infection in the United States. Clinical Infectious Diseases 49, 878-884 (2009).

70. Kapperud, G. et al. Risk factors for Toxoplasma gondii infection in pregnancy: Results of a prospective case-control study in Norway. American Journal of Epidemiology 144, 405-412 (1996).

71. Du, F. et al. Soil contamination of Toxoplasma gondii oocysts in pig farms in central China. Veterinary Parasitology 187, 53-56 (2012).

72. Gao, X., Wang, H., Wang, H., Qin, H. \& Xiao, J. Land use and soil contamination with Toxoplasma gondii oocysts in urban areas. Science of the Total Environment 568, 1086-1091 (2016).

73. Liu, X. et al. Detection of Toxoplasma gondii in chicken and soil of chicken farms in Nanjing region, China. Infectious Diseases of Poverty 6, 62 (2017)

74. Wang, M. et al. Detection of Toxoplasma gondii oocysts in soils in Northwestern China using a new semi-nested PCR assay. BMC Veterinary Research 10, 238 (2014).

75. Du, F. et al. Survey on the contamination of Toxoplasma gondii oocysts in the soil of public parks of Wuhan, China. Veterinary Parasitology 184, 141-146 (2012).

76. Ding, H., Gao, Y., Deng, Y., Lamberton, P. H. L. \& Lu, D. A systematic review and meta-analysis of the seroprevalence of Toxoplasma gondii in cats in mainland China. Parasites \& Vectors 10, 27 (2017).

77. Wu, S. et al. Seroprevalence of Toxoplasma gondii infection in pet dogs in Lanzhou, Northwest China. Parasites \& Vectors 4, 64 (2011).

78. Wang, M. et al. Serological survey of Toxoplasma gondii in Tibetan mastiffs (Canis lupus familiaris) and yaks (Bos grunniens) in Qinghai, China. Parasites \& Vectors 5, 35 (2012).

79. Alvarado-Esquivel, C., Estrada-Martínez, S. \& Liesenfeld, O. Toxoplasma gondii infection in workers occupationally exposed to unwashed raw fruits and vegetables: a case control seroprevalence study. Parasites \& Vectors 4, 235 (2011).

80. Xu, Y., Shen, Z., Bao, T., Peng, G. \& Wang, Z. Nantong shi rou ru shipin zhiye renqun gongxing chong kangti de jiance [Detection of Toxoplasma antibodies in occupational population of meat and milk food in Nantong City]. Journal of Nantong University (Medical Sciences) 10, 99-100 (1990).

81. Zhao, Z., Zhang, G., Li, Y., Hao, F. \& Liu, B. The investigation of Toxoplasma gondii infection in Laiyang, Shandong Province. Shandong yixue yuan xuebao 18-21 (1985).

82. Zhou, X., Zhao, Y., Yan, G. \& Zhang, C. Seroepidemiological survey of Toxoplasma gondii infection among employees in a pork food processing enterprise. Chinese. Journal of Schistosomiasis Control 30, 694-695 (2018).

83. Kourenti, C. \& Karanis, P. Evaluation and applicability of a purification method coupled with nested PCR for the detection of Toxoplasma oocysts in water. Letter in Applied Microbiology 43, 475-481 (2006).

84. Arkush, K. D. et al. Molecular and bioassay-based detection of Toxoplasma gondii oocyst uptake by mussels (Mytilus galloprovincialis). International Journal for Parasitology 33, 1087-1097 (2003). 
85. Su, C., Shwab, E. K., Zhou, P. \& Zhu, X. Moving towards an integrated approach to molecular detection and identification of Toxoplasma gondii. Parasitology 137, 1-11 (2010).

86. Su, C., Zhang, X. \& Dubey, J. P. Genotyping of Toxoplasma gondii by multilocus PCR-RFLP markers: A high resolution and simple method for identification of parasites. International Journal for Parasitology 36, 841-848 (2006).

87. Grigg, M. E., Ganatra, J., Boothroyd, J. C. \& Margolis, T. P. Unusual abundance of atypical strains associated with human ocular toxoplasmosis. The Journal of Infectious Diseases 184, 633-639 (2001).

\section{Acknowledgements}

We acknowledge the funding support from the Thousand Talents Plan of the Chinese Government (NO. WQ2013630172).

\section{Author contributions}

A.L. conception of the study, study design, methodology selection, performance of real-time PCR, quantitative real-time PCR, genotyping, sequencing, data analysis, interpretation of the results, writing manuscript; L.M. collection of samples, contribution in laboratory work; I.K. - contribution in laboratory work (PCR), writing manuscript, data analysis, statistics, graphical presentation of figures and tables, selection of references; X.Z. collection of samples, contribution in PCR; X.L. - collection of samples, flocculation; P.K. - conception of the study, financial support, contribution in data analysis, revision of manuscript.

\section{Competing interests}

The authors declare no competing interests.

\section{Additional information}

Supplementary information is available for this paper at https://doi.org/10.1038/s41598-019-54073-6.

Correspondence and requests for materials should be addressed to A.L.

Reprints and permissions information is available at www.nature.com/reprints.

Publisher's note Springer Nature remains neutral with regard to jurisdictional claims in published maps and institutional affiliations.

Open Access This article is licensed under a Creative Commons Attribution 4.0 International License, which permits use, sharing, adaptation, distribution and reproduction in any medium or format, as long as you give appropriate credit to the original author(s) and the source, provide a link to the Creative Commons license, and indicate if changes were made. The images or other third party material in this article are included in the article's Creative Commons license, unless indicated otherwise in a credit line to the material. If material is not included in the article's Creative Commons license and your intended use is not permitted by statutory regulation or exceeds the permitted use, you will need to obtain permission directly from the copyright holder. To view a copy of this license, visit http://creativecommons.org/licenses/by/4.0/.

(C) The Author(s) 2019 